\title{
A etnografia como categoria de pensamento na antropologia moderna
}

\author{
GILMAR Rocha
}

\begin{abstract}
resumo As inúmeras possibilidades e problemas colocados pela etnografia à reflexão epistemológica na antropologia fazem dela uma importante categoria de pensamento, por meio do qual se revela o sentido do ofício ("fazer") dos antropólogos. Assim, a etnografia pode ser vista como um gênero de performance cujo significado ultrapassa as fronteiras das culturas nativas, alcançando o campo cultural do antropólogo. Performance, neste estudo, representa um modo de auto-reflexividade social em que o antropólogo, através da narrativa, busca ampliar o "campo" da antropologia. Apontar alguns momentos desse processo de reflexividade etnográfica é o objetivo deste texto, sendo a obra de Marcel Mauss (1872-1950), um exemplo privilegiado.
\end{abstract}

palavras-chave Etnografia. Performance. Narrativa. Marcel Mauss.

"Agora somos todos nativos..." Clifford Geertz

\section{O ofício de antropólogo}

Por muito tempo, a etnografia correspondeu à descrição dos costumes de um povo ou tratado sobre as gentes. Apesar desses costumes, de gentes e povos representarem diferentes formas de experiências culturais, em geral diferentes da cultura do etnógrafo, nutria-se a ilusão de que tais descriçóes eram isentas de juízos de valor. O que muda com a institucionalizaçáo da antropologia como ciência social nos séculos XIX/XX é que as descriçóes sobre as experiências humanas e culturais, de povos e gentes diferentes, passam a considerar a pessoa do antropólogo. Se até esse momento a figura do etnógrafo era distinta da do antropólogo, no início do século XX elas se fundem em uma única personagem. $\mathrm{O}$ resultado foi o surgimento do antropólogo social ou cultural como o conhecemos hoje. Um profissional com formação acadêmica e que tem no trabalho de campo um método de pesquisa, a "etnografia", sendo a legitimidade desta conquistada por meio da observação-participante. Desde então, etnografia tornou-se sinônimo de trabalho de campo, embora estas sejam atividades distintas.

Os antropólogos são unânimes quanto à inexistência de receitas para se fazer trabalho de campo. Mesmo que tenham sido produzidos manuais de etnografia, tais como o Guia Prático de Antropologia, publicado em 1874, e o Manual de Etnografia, de Marcel Mauss, originalmente publicado em 1947, o trabalho de campo consiste em uma experiência profundamente marcada pela singularidade sócio-histórica. Isto não significa a ausência de rigor metodológico e analítico do antropólogo, ao contrário, a etnografia garante novas possibilidades teóricas ao "campo epistemológico" da disciplina, exatamente porque aí reside o que DaMatta (1978) denominou anthropological blues, ou seja, o lado extraordinário, menos rotineiro, porém, mais humano do trabalho de campo. Por este motivo é possível considerar a etnografia como um gênero de performance, ou seja, uma forma de ação simbólica densa e profundamente rica em reflexóes epistemológicas.

Nas últimas décadas, a etnografia tornou-se "objeto" privilegiado de reflexóes nos meios antropológicos nacionais e internacionais ${ }^{1}$. Mesmo

1. Para um balanço crítico sobre a produção etnográfica contemporânea, ver Marcus e Cushman (2003). 
que esta seja uma questáo predominante no contexto norte-americano, como sugere Trajano Filho (1988), o estatuto da etnografia sempre mereceu a atenção dos antropólogos ao longo da história da disciplina no século XX. O entendimento da etnografia como uma categoria de pensamento não exclui sua dimensáo performativa o que, em termos geertzianos, designa o "fazer" do antropólogo. Por este prisma, pensamento e ação, razáo e afetividade não estão separados na experiência etnográfica. Portanto, é como categoria de pensamento e ação performativa que a etnografia adquire relevância sociológica e epistemológica na compreensáo do ofício do antropólogo e na construçáo do "campo" da antropologia ${ }^{2}$.

\section{Cultura e missáo da antropologia em tempo de guerra}

A década de 20 é um marco na história da antropologia social e cultural. Pode-se considerá-la como o "período clássico" da antropologia

2. A categoria "etnografia" tem sido utilizada com sentidos variados ao longo da história da antropologia moderna. Ora será vista como método qualitativo desenvolvido no trabalho de campo, ora estará relacionada à escrita do antropólogo - o texto monográfico propriamente dito - ora, ainda, a ênfase recaindo sobre os discursos, as formas de diálogos, estabelecidos entre nativos e antropólogos no encontro etnográfico. Aqui, a compreensão da etnografia como categoria de pensamento com qualidades performativas tem como pressuposto: 1) o fato de que a etnografia é "boa para pensar" a constituição do campo antropológico; 2) ampliar o entendimento da etnografia como processo epistemológico que vai do campo ao texto; 3) por fim, sem perder de vista todas as implicaçóes teóricas relacionadas às dimensôes metodológica, ritualística, cognitiva nesse processo, a aproximação com a performance visa destacar o caráter reflexivo da narrativa etnográfica como um "modelo de ação", cuja fonte de inspiração são as análises de Austin (1990) sobre os atos performativos da linguagem, os modelos "de" e "para" realidade na interpretação de Geertz (1978) e o "comportamento restaurado" de Schechner, ver Silva (2005). moderna. Algumas das obras mais significativas que marcaram a história da disciplina, servindo, muitas vezes, como paradigmas do saber antropológico, surgem neste momento. Além de Argonautas do Pacifico Ocidental (1922), de Bronislaw Malinowski, alguns outros clássicos da etnografia modernista vieram a público: na Inglaterra, a versão resumida de The Golden Bough (1922), de Sir James George Frazer, e The Andaman Islanders (1922), de Radcliffe-Brown; na França, La Mentalité primitive (1922), de Lucien Lévy-Bruhl, e Essai sur le don (1925), de Marcel Mauss; nos Estados Unidos, o trabalho de Franz Boas Anthropology and Modern Life (1928) e Coming of Age in Samoa (1928), de Margaret Mead. Isto para ficarmos com alguns dos principais textos representativos de cada uma dessas antropologias nacionais ${ }^{3}$.

No período entre-guerras, o mundo ocidental viveria uma profunda crise de consciência, que seria acompanhada da intensificação dos estudos sobre as sociedades primitivas, consideradas como "modos de vida autênticos". Parte da motivação em direção ao "mundo primitivo" seria fornecida por uma certa concepção antropológica de "campo", visto então como uma espécie de "laboratório natural" - logo, um lugar livre das "impurezas” da civilização

3. A antropologia produzida até o momento da Primeira Guerra Mundial seria marcada pelas perspectivas do evolucionismo social e do difusionismo cultural. Neste momento, predominava ainda a representação do "etnógrafo amador" (missionários, militares, viajantes etc.), quando não a do "antropólogo de gabinete", sendo, nesse caso, o nome de Sir James George Frazer o mais lembrado. Mas desde fins do século XIX, experiências como a famosa Expedição ao Estreito de Torres (Oceania) em 1888/89, que contou com a participação de eminentes antropólogos como W. H. R. Rivers e C. G. Seligmann a convite de Alfred C. Haddon, representaram significativa contribuição para a institucionalização da antropologia social e cultural moderna. Para Grimshaw (2001), esta expedição celebra o nascimento da Antropologia Moderna. 
- e, ao mesmo tempo, o local de uma experiência privilegiada para a iniciação do antropólogo profissional e do desenvolvimento teórico da antropologia.

Sem perder de vista as especificidades das antropologias nacionais, o quadro cultural dos anos 20-40 exigiu dos antropólogos da época a necessidade de realização de uma dupla tarefa. De um lado, a antropologia, ao imaginar o fim ou desaparecimento das culturas primitivas frente à marcha inelutável do processo civilizatório ocidental, colocava ao antropólogo a "missáo salvacionista" de resguardar esses patrimônios culturais (e porque náo dizer "naturais") da humanidade, garantindo sua sobrevivência mesmo que por meios ficcionais, como narrativa etnográfica. Por outro lado, essas mesmas sociedades ameaçadas de desaparecimento exerceram grande fascínio no meio intelectual, artístico e antropológico, favorecendo assim o desenvolvimento de uma crítica cultural na medida em que estas sociedades apresentavam alternativas culturais frente aos problemas introduzidos pela marcha da civilização ocidental. Antropólogos como Ruth Benedict expressariam de maneira dramática este quadro de crítica cultural em termos da tensão indivíduo/sociedade característica da sensibilidade modernista da época ${ }^{4}$. Assim, a importância deste "fascínio pelo primitivo" reside no fato de este ter provocado a necessidade de se repensar o significado da cultura, abrindo a antropologia para o campo do relativismo cultural e, por conseguinte, engendrando a crítica ao etnocentrismo.

A partir de então, o fazer etnográfico e o conceito de cultura ganham atenção especial dos antropólogos, estimulando cada vez mais novas pesquisas e discussóes teóricas. O resultado imediato foi a produçáo de textos exemplares, tais como O Superorgânico (1919), de

4. A este respeito ver Handler (1990).
Alfred Kroeber, e o ensaio de Edward Sapir, "Cultura autêntica e espúria", publicado em 1924, contribuindo para a renovaçáo do significado de cultura a ponto de, na avaliaçáo de Stocking Jr. (1983), este último representar uma espécie de "documento de fundação" da sensibilidade etnográfica nos anos 20. Com efeito, uma das grandes contribuiçóes de Sapir para a antropologia cultural deste momento foi a de deslocar o conceito de cultura do campo factual das tradiçóes, costumes etc., empurrado-o para o plano da cogniçáo 5 .

Por outro lado, também a aproximaçáo da antropologia com certas experiências artísticas, como o movimento surrealista, contribuiu para aprofundar a crítica cultural dos antropólogos aos males produzidos pela civilização, ainda que não tenha sido possível fugir completamente à encenação do exótico. A Missão Dakar-Djibouti, realizada na África entre 1931-1933, liderada por Marcel Griaule, e da qual participou Michel Leiris é, sem dúvida, o melhor exemplo do que Clifford (1998) classificou de "surrealismo etnográfico": um movimento cultural que, além de produzir estudos profundos sobre sociedades africanas como os Dogons, também possibilitou a realização de uma grande reflexão sobre a própria sociedade francesa em geral, e a antropologia em particular. Logo depois seria criado o Musée de l'Homme (1938), um centro cultural cujo título condensa o espírito maussiano do fato social total. Mais do que um lugar de exposição dos artefatos culturais exóticos, o Museu do Homem era também o centro de pesquisas e lugar de reunião da arte com a antropologia. $\mathrm{Na}$ verdade, este se tornou

5. Sapir pensa a cultura como um sistema de comunicação no qual a linguagem classifica e organiza as experiências sensíveis fazendo a mediação entre a cultura e o pensamento cognitivo. A partir do conceito de cultura se criticava o "estilo de vida" desenvolvido pela civilização ocidental em sintonia com as críticas de Freud, por exemplo. 
um dos principais símbolos da antropologia moderna em tempos de guerra, cuja missão era a de salvaguardar a cultura do homem, ameaçada de extinção.

\section{A instituiçáo do campo}

O antropólogo, ao deslocar-se de sua sociedade para uma outra distante, buscava apreender, sem a interferência de terceiros (viajantes, missionários, militares e outros), a realidade concreta ou, no dizer de Mauss, buscava "fazer como eles [os historiadores]: observar o que é dado. Ora, o dado é Roma, é Atenas, é o francês médio, é o melanésio dessa ou daquela ilha, e não a prece, ou o direito em si” (1974: 181). Para estudar o concreto (no sentido da realidade social), é preciso "estar lá", é preciso ir ver de perto o "nativo". Desde então, a viagem tornou-se algo mais do que uma aventura ou experiência exótica; tornou-se uma estratégia fundamental no processo de institucionalização do trabalho de campo e, portanto, de disciplinarizaçáo da antropologia ${ }^{6}$.

Sem dúvida o clássico Argonautas do Pacífico Ocidental, de Malinowski, constitui o modelo exemplar do texto etnográfico. Desde sua publicação tem servido de paradigma metodológico do trabalho de campo, não sendo exagero dizer que a experiência etnográfica do trabalho de campo tornou-se, desde então, sinônimo de "observação participante" e, via de regra, os textos etnográficos posteriores passaram a seguir o seu "modelo realista".

É bem verdade que o trabalho de campo é visto, salienta Copans, como "uma experiência

6. Para uma análise do papel das viagens na instituição do campo antropológico ver Clifford (1997). Apesar de Lévi-Strauss ter anunciado o "fim" das viagens, sem dúvida a "viagem etnográfica" do antropólogo profissional consiste num momento especial do trabalho de campo, haja vista sua qualidade performativa. A propósito, este é exatamente o caso de Tristes Trópicos. aureolada com os prestígios do exotismo" (1981: 59), assumindo assim, muitas vezes, as feiçôes de um mito ${ }^{7}$. Não se nega a importância do trabalho de campo, seu caráter extraordinário e, sem dúvida, a experiência exótica que ele encerra. Contudo, o significado mítico da aventura malinowskiana está longe de ser plenamente realizado e ritualizado pela maioria dos antropólogos ${ }^{8}$.

Se, inicialmente, o trabalho de campo representou uma oportunidade de ultrapassar os limites teóricos e metodológicos impostos pela "antropologia de gabinete" - na medida em que abriu a possibilidade de se estudar in loco a vida, os costumes, os mitos, os ritos, as formas de estruturação e organização das sociedades primitivas com o tempo, este se tornou uma quase exigência na produção de conhecimento e desenvolvimento da própria disciplina, além de designar uma espécie de "rito de passagem" (em especial, de iniciação) ao aspirante a antropólogo? .

7. Também James Clifford chama atençâo para o "mito" do trabalho de campo: "A observação participante obriga seus praticantes a experimentar, tanto em termos físicos quanto intelectuais, as vicissitudes da tradução. Ela requer um árduo aprendizado lingüístico, algum grau de envolvimento direto e conversação e, freqüentemente, um 'desarranjo' das expectativas pessoais e culturais. É claro que há um mito do trabalho de campo. A experiência real, cercada como é pelas contingências, raramente sobrevive a esse ideal; mas como meio de produzir conhecimento a partir de um intenso envolvimento intersubjetivo, a prática da etnografia mantém um certo status exemplar. Além disso, se o trabalho de campo foi durante algum tempo identificado a uma ciência totalizante, a 'Antropologia', tais associações não são necessariamente permanentes. Os atuais estilos de descrição cultural são historicamente limitados e estão vivendo importantes metamorfoses" (1998: 20).

8. Para Kuper (1978) a experiência de Malinowski pode ser vista como "mito de fundação".

9. O trabalho de campo pode ser visto como uma espécie de instituição, no sentido atribuído por Douglas (1998): trata-se de uma convenção que, como tal, se autopolicia, define regras de comportamento, estabelece sistemas de pensamento e se legitima em torno de algum princípio fundante. 
Geralmente durante o trabalho de campo os antropólogos são temporariamente retirados do convívio de seus familiares e amigos para viverem uma outra experiência social extraordinária, tal como acontece a muitos noviços nas sociedades primitivas. O resultado é, após o antropólogo ter experimentado situaçóes limites de convívio social com o "outro", uma mudança de sua posição social, acompanhada de uma profunda operação cognitiva. Ao final do processo é a própria percepção, os sentidos, os valores, enfim, o "ponto de vista" do antropólogo que se modifica. Pode-se vislumbrar um verdadeiro processo de "educação dos sentidos" cujo resultado é a formação de uma refinada sensibilidade antropológica. As consideraçóes de Roberto Cardoso de Oliveira (2000) sobre o processo de domesticação do olhar, do ouvir e do escrever - espécies de "faculdades do entendimento" sociocultural inerentes ao "campo" das ciências sociais e humanas - no ofício do etnógrafo, dão bem o tom do ethos antropológico ${ }^{10}$.

$\mathrm{Na}$ verdade, não é somente a identidade do "nativo" que está sendo construída no trabalho de campo, mas também a persona do antropólogo. Parafraseando Condominas, Pulman diz que "o momento mais importante de nossa vida profissional corresponde ao tempo de trabalho no campo: ao mesmo tempo nosso laboratório e nosso rito de passagem, o campo transforma cada um de nós em um verdadeiro antropólogo" (1988: 22). Essa também é a conclusão de Boon (1993: 24), para quem

A identidade contemporânea do antropólogo profissional baseia-se, em minha opiniáo corretamente, no trabalho de campo ideal e na prática. Isto não quer dizer que a história da disciplina comece com o trabalho de campo nem que os antropólogos tenham que fazê-lo,

10. A noção de ethos, na definição de Bateson (1990), remete a um sistema cultural de normalizaçấo e organização dos instintos e emoçôes dos indivíduos. mas táo somente que o trabalho de campo é o epítome do que fazem os antropólogos quando escrevem.

A partir de tais observaçóes, pode-se afirmar, então, que a modelagem da persona do antropólogo, em grande medida, está relacionada com sua experiência de campo. "É no campo que o antropólogo forma sua identidade», sentencia Kilani (1994). Por vezes a construção da identidade social do "nativo" e do "antropólogo" adquire contornos de uma relação "totêmica" em que os nomes Malinowski, Evans-Pritchard, Firth e Turner estão intimamente associados às culturas Trobriand, Nuer, Tikopia e Ndembu, respectivamente. De acordo com Kilani (1994:49):

A monografia constrói a imagem unificada de um antropólogo em simbiose com uma cultura “das gentes". As "gentes" são elas mesmas configuradas nos limites do texto etnográfico, assim como a diversidade das formas sociais e culturais é estabilizada através de uma representação "padrão". Em suma, a monografia surge nesse sentido como um tipo de ícone. Ela conjuga, segundo os termos de Atikinson, um "autor" e um "campo" (uma cultura, uma sociedade) de uma representação concreta: o "campo" como o "autor" são com efeito "reconhecidos" - pode se dizer então - no e através do mesmo processo de leitura da monografia. É por meio das monografias, dos homens e das mulheres daquelas "culturas", dos "campos", que os autores são identificados e classificados. É este um tipo de classificação "totêmica" (...) a base textual que nos permite identificar emblematicamente Evans-Pritchard aos Nuers, Margaret Mead aos Samoanos, Marcel Griaule aos Dogons... e inversamente.

Por outro lado, não só as experiências vividas pelo antropólogo em campo são fundamentais 
para sua formação, mas também o aprendizado de certos valores da cultura científica. $\mathrm{O}$ universo científico comporta um conjunto de regras, valores e procedimentos éticos aos quais o pesquisador deve, até certo ponto, submeterse. Este processo exige que o iniciado partilhe de um sistema de crenças como, por exemplo, racionalidade, ruptura epistemológica, objetividade etc., que devem ser por ele aprendidas e experimentadas $^{11}$.

De fato, tanto a compreensão e interpretação de outras culturas, quanto o desenvolvimento teórico e metodológico da antropologia deve muito às experiências do trabalho de campo. Apesar das recentes críticas epistemológicas à etnografia, mesmo as posiçóes mais radicais não supóem sua eliminação no campo da antropologia, mas reconhecem a necessidade de se repensar e refletir sobre seu ideal "cientificista”. Com isso, muito das questóes que envolvem a experiência etnográfica do antropólogo moderno são colocadas sob suspeita.

\section{A favor do método}

A canonização da etnografia, a partir do trabalho de campo de Malinowski entre os Trobriandeses (Pacífico Ocidental), não impediu que outras modalidades de experiências etnográficas fossem elaboradas ou que fossem sugeridas por outras interpretaçóes em anos recentes (pós-60). Não deixaram de provocar certo incômodo na comunidade antropológica, por exemplo: Naven, de Gregory Bateson, nos anos 30; The City of Women, de Ruth Landes,

11. Complementando a nota anterior, o conceito de habitus, tal qual utilizado por Bourdieu (1983) em sua sociologia da ciência, representa a outra metade desse processo de "educação dos sentidos". Assim, ampliando o sentido dessa sensibilidade etnográfica, podemos ver em todo este processo uma espécie de "educaçáo sentimental”, na qual o principal aprendiz é antropólogo, sugere Geertz (1978). nos anos 40; Tristes Tropiques, de Lévi-Strauss nos anos 50; e The Teachings of Don Juan, de Carlos Castañeda nos anos 60. Antes de representarem "desvios" frente às convençóes disciplinares estes trabalhos são indicadores do que alguns antropólogos chamam de "experiência indisciplinada" da etnografia ${ }^{12}$. Tais trabalhos abriram espaço para que a etnografia deixasse de ser vista única e exclusivamente como estratégia metodológica do trabalho de campo. Outras estratégias metodológicas desenvolvidas na construção textual do objeto antropológico, então, passaram a ser teorizadas ${ }^{13}$.

Isto fica claro quando se têm em consideração as observaçóes de um antropólogo como Geertz acerca da reflexividade epistemológica inerente ao trabalho de campo ${ }^{14}$. Em prefácio datado de 1968, no recém editado Islam Observed, Geertz (2004:12), destacava a importância do trabalho de campo no processo de interpretação de uma cultura, diz ele:

O trabalho de um antropólogo, a despeito do tema declarado, tende a ser uma expressão de sua experiência de pesquisa, ou, mais precisamente, do que a experiência de pesquisa faz a ele. Isso certamente vale no meu caso. O trabalho de campo tem sido para mim intelectualmente (mas não só intelectualmente) formativo, fonte não só de hipóteses isoladas, mas de pa-

12. A idéia de "experiência indisciplinada" é, na verdade, o reconhecimento daquilo que Fayereband denunciava em Contra o método (1989). Por outro lado, esta idéia não contradiz o seu processo histórico de disciplinarização conforme sugere a interpretação de Oliveira (1988).

13. Mais do que uma questão de método, etnografia e trabalho de campo são experiências de natureza epistemológica e ontológica, como o sugerem alguns filósofos e antropólogos, dentre eles: MerleauPonty (1989), Kilani (1994), Casal (1996), Clifford (1998).

14. Essas observações relativas a Geertz me foram sugeridas pelo parecerista do artigo, a quem agradeço. 
drôes inteiros de interpretação social e cultural. O conjunto do que eu vi (ou penso ter visto) na história, eu o vi (ou penso ter visto) antes nos estreitos limites de cidades e aldeias camponesas.

Sem perder de vista os padróes antropológicos de interpretação social e cultural, passados exatos vinte anos, Geertz (1997:14) trouxe a público em 1988, Works and Lives - The Anthropologist as Autor, trabalho no qual o antropólogo chama a atenção para a eficácia simbólica da retórica etnográfica. É visível, neste caso, a mudança de foco do antropólogo, do campo ao texto:

A habilidade dos antropólogos em nos fazer tomar a sério o que dizem tem menos a ver com seu aspecto factual ou seu ar de elegância conceptual, que com sua capacidade para nos convencer de que o que dizem é o resultado de termos podido penetrar (ou, se prefere, de termos sido penetrados por) outra forma de vida, de havermos, de um outro modo, realmente ter "estado lá". E na persuasão de que tendo este milagre invisível ocorrido, houve intervenção da escrita.

Ou seja, as monografias antropológicas revelam tanto a "visão de mundo" do autor (o seu estilo "literário") quanto à visão dos nativos que este estuda. Mas, apesar das críticas ao caráter "autoral" e "ficcional" dos textos etnográficos, a importância do trabalho de campo pode ser corroborada pelo que nos diz Mariza Peirano. Após argumentar $A$ favor da etnografia, conclui a antropóloga (1995: 57):

Novas análises e reanálises virão comprovar a fecundidade teórica do trabalho etnográfico. Elas certamente irão reforçar a convicção central dos antropólogos: a de que a prática etnográfica - artesanal, microscópica e detalhista - traduz, como poucas outras, o reconhecimento do aspecto temporal das explicaçóes. Longe de repre- sentar a fraqueza da antropologia, portanto, a etnografia dramatiza, com especial ênfase, a visão weberiana da eterna juventude das ciências sociais.

É preciso considerar, no entanto, que o método etnográfico do trabalho de campo não aponta somente para o estilo literário, o aspecto artesanal e microscópico ou o caráter temporário das explicaçóes antropológicas, fazendo-nos ver a "eterna juventude" da antropologia. $\mathrm{Na}$ verdade, trata-se de uma prática incorporada ao fazer da antropologia que denota seu traço distintivo e específico frente às outras ciências sociais. $\mathrm{O}$ trabalho de campo não é exclusividade da antropologia mas é uma de suas tarefas básicas, senão a principal. Pode-se dizer que a experiência etnográfica constitui-se no traço identitário da disciplina.

Os antropólogos concordam, hoje, com o caráter experimental da etnografia. Nessa perspectiva torna-se inegável a contribuição da etnografia para o próprio desenvolvimento epistemológico da disciplina ao se relativizar rígidos padróes e modelos teóricos e metodológicos. $\mathrm{O}$ método do trabalho de campo em antropologia é, nesse caso, exemplar. Nele, o encontro etnográfico do sujeito e do objeto do conhecimento transpóe os limites do trabalho de campo para o próprio campo da antropologia, exigindo assim uma dupla hermenêutica enquanto exercício profundo de auto-reflexividade ${ }^{15}$.

A visão realista da etnografia como estratégia metodológica de trabalho de campo cede

15. Segundo Boaventura Santos, com a crise dos paradigmas da ciência moderna impôs-se a necessidade de uma reflexão hermenêutica que procura "romper o círculo vicioso do objeto-sujeito-objeto, ampliando o campo da compreensão, da comensurabilidade e, portanto, da intersubjetividade e, por essa via, vai ganhando para o diálogo eu/nós-tu/vós o que agora não é mais que uma relação mecânica eu/nós-eles/coisas" (1989: 16). A tradicional relação epistemológica "eucoisa" desloca-se para relação hermenêutica "eu-tu". 
lugar a uma visão hermenêutica na qual o reconhecimento da "experiência indisciplinada" do ofício do antropólogo e as "retóricas" do texto antropológico colocam a etnografia no campo das reflexóes epistemológicas. Quando a etnografia passa a integrar o campo do conhecimento epistemológico, transformando-se em uma estimulante categoria de pensamento sobre a experiência e a escrita antropológica, abre-se espaço para falar em "etnografia do pensamento antropológico". Em outras palavras, sem perder de vista que "a construção do texto antropológico começa no campo" (Kilani 1994: 46), a etnografia deixa de ser vista somente como uma estratégia metodológica e passa a significar um empreendimento textual situado em contextos históricos e culturais específicos.

\section{Performance etnográfica}

Para alguns antropólogos a escrita etnográfica dramatiza uma estratégia específica de autoridade que se revela, basicamente, em certos modos de representação. Sem entrar na especificidade de cada um deles, vale registrar o fato de que "os processos experiencial, interpretativo, dialógico e polifônico são encontrados, de forma discordante, em cada etnografia, mas a apresentaçáo coerente pressupóe um modo controlador de autoridade", como dirá o historiador James Clifford (1998: 58). Vimos que também Geertz póe em destaque a importância da experiência e da escrita na definiçáo da própria etnografia e, portanto, dessas estratégias de construção da autoridade etnográfica. Afinal, a etnografia está, inextricavelmente, presa ao campo da escrita. $\mathrm{Na}$ verdade, trata-se de uma escrita que guarda a memória da experiência etnográfica, agora traduzida para uma forma textual.

Se, como pensa Geertz, o etnógrafo "inscreve" o discurso social, anotando-o, objetificando-o e autorizando-o a existir textual e culturalmente, isto é, se o etnógrafo fixa o discurso social no modo de uma escrita narrativa como "registro de consultas sobre o que o homem falou" (1978: 41), então a etnografia é, ela mesma, uma forma de inscriçáo do discurso antropológico moderno, pois é através da experiência e da escrita etnográfica que a ciência antropológica se modela cultural e historicamente. Assim, etnografia é também, além do registro textual de uma fala nativa, um modo cultural de escrita antropológica.

Com efeito, o que a escrita etnográfica fixa não é somente o dito no fluxo do discurso social, "o que o homem falou", mas, sobretudo, um modo de pensamento social etnográfico. As etnografias, ao representarem sistemas simbólicos de crenças, ritos, mitos e religióes, não apenas descrevem ou falam sobre o modo de pensamento dos "nativos". A maneira como estes sistemas são descritos revelam, por sua vez, o modo como este pensamento foi organizado textual e narrativamente. A escrita etnográfica, portanto, ao expor a cultura do "outro", informa-nos também sobre a estrutura e a organizaçáo narrativa do texto, revelando assim parte da cultura do próprio antropólogo. Em última instância, quem fala é o antropólogo, embora sua fala não seja a única ${ }^{16}$.

Pode-se afirmar então que etnografias são narrativas, expressóes de certo tipo de experiência

16. Relativizando as teorias que vêem na escrita um modo de domesticaçáo do pensamento ou limitaçáo da experiência compartilhada pela oralidade, a exemplo do poder da fala nos rituais mágicos, também a escrita promove uma operação simbólica de ampliar o mundo das experiências e do pensamento social. Se, por um lado, a escrita individualiza o mundo da experiência, por outro lado universaliza quando lhes possibilita viajarem por meio dos textos no tempo e no espaço. Haja vista o quanto nossas sociedades trabalham com a idéia do "mundo fechado" dos analfabetos. Daí, a crítica dirigida à antropologia interpretativa de Geertz, reside no fato de que nesta, mais do que a fala do nativo, o que se ouve é a voz de Geertz "por sobre os ombros dos balineses". 
e, portanto, formas de ação e representação que podem ser vistas como "performances" na medida em que revelam um processo de reflexividade hermenêutica sobre as maneiras como os homens interpretam, sentem, experimentam e vivem suas culturas, sobretudo quando a cultura em questão é a do próprio antropólogo ${ }^{17}$.

As narrativas etnográficas expressam muitas vezes conflitos de experiências entre emoção e razão, não totalmente domesticados pelas convençóes disciplinares. Nem por isso estas experiências deixam de ser guiadas por "estruturas narrativas". Como propóe Bruner, "as estruturas narrativas servem como guias interpretativos; elas nos dizem o que constitui dados, define os tópicos de estudo, e ressalta o sentido da construção na situação de campo quando transforma o estranho em familiar" (1986: 147). No entanto, estas estruturas narrativas devem ser vistas mais como "estruturas performativas", nos termos de Sahlins (1990), do que como "estruturas prescritivas", nos padróes radcliffe-brownianos. Com isso abre-se a possibilidade de pensar a narrativa etnográfica não só em termos de uma etnografia da performance, mas também de uma performance da etnografia.

Sabe-se que os anos 70 marcam o encontro da antropologia com a arte da performance no campo das ciências sociais. Mas é a luz dos desdobramentos sociológicos da fenomenologia de Schutz, da etnometodologia de Garfinkel, da dramaturgia social de Goffman assim como dos movimentos artísticos modernos - como o Surrealismo, o Dadaísmo, o Futurismo e demais manifestaçóes contraculturais na música, na dança, no teatro e os movimentos da living art, body art e outros - que se pode compreender o

17. É como gênero discursivo por meio do qual se trocam experiências, se mesclam sentidos e tradições diferentes (oral/escrito; nativo/antropólogo) à maneira de uma atividade artesanal que a narrativa, no sentido benjaminiano, se mostra referencial neste texto. Ver Benjamin (1994). desenvolvimento de uma teoria da performance na chamada antropologia pós-moderna. Na verdade, esse percurso náo nos leva a uma situação estável e definida sobre a relação antropologia/ performance. Náo significa isto que as etnografias produzidas antes dos anos 70 não sejam narrativas performáticas. $\mathrm{O}$ fato é que a chamada pós-modernidade tornou a relação etnografia/ performance um problema visível.

Uma antropologia da performance nos possibilita assim uma dupla interpretação: de um lado, com a descrição de uma performance cultural qualquer como espetáculo, evento ou ritual, e, do outro lado, com o estudo performativo de toda e qualquer etnografia - na medida em que as etnografias, envolvendo as experiências do campo ao texto, dramatizam uma ação reflexiva. Embora a etnografia da performance e a performance da etnografia sejam perspectivas distintas, uma mesma obra permite que se articule as duas. Na verdade, a etnografia não fala somente de uma única cultura ${ }^{18}$.

Enquanto um tipo de experiência e narrativa, a etnografia é auto-referencial, pois representa uma forma de ordenar o mundo tanto do "eu" quanto do "outro". Ao integrarem narrativas etnográficas, os conceitos antropológicos de cultura, mito, campo etc., organizam de maneira coerente a cultura e dão significado às experiências humanas. Nesse sentido, fica-se

18. Basicamente, existem duas linhas de investigaçôes antropológicas sobre a performance: de um lado, a linha de investigação da performance na linguagem, cuja base encontra-se nos trabalhos de Wittgenstein, Austin e Searle, culminando nas contribuições antropológicas de Bauman e outros sobre a "etnografia da fala". Do outro lado, a "antropologia da performance" de Victor W. Turner, que se converte em um dos melhores exemplos de performance cultural da antropologia pós-moderna, a qual Langdon (1999) batiza de "enfoque da performance como drama social". Nesse caso, o teatro tem servido de fonte primordial de inspiração à antropologia da performance, ver Silva (2005). 
muito próximo da idéia de "invenção da cultura” de Roy Wagner (1981). Num movimento dialético de controle (às vezes "inconsciente") do campo etnográfico e da invenção cultural, os antropólogos tornam inteligíveis as práticas e experiências dos "outros", na medida em que objetificam "nativos" e "culturas". Mas, ao fim desse processo, segundo Wagner, o que de fato ocorre é que "o que o pesquisador de campo inventa, portanto, é seu próprio entendimento; as analogias criadas por ele são extensóes de suas próprias noçóes e as referências de cultura são transformadas pelas suas experiências das situaçóes de campo" (1981: 12). Inventando "outras" culturas, os antropólogos constroem para si mesmos o sentido de cultura, afinal,

o estudo da cultura é, de fato, nossa cultura; operada através de nossas formas, criada em nossos termos, seguindo nossas palavras e conceitos para seus significados, e nos recriando através de nossos esforços (1981: 16).

De resto, pode-se dizer que as etnografias são "invençóes", "ficçóes" (no sentido de fictio, "construçóes") modeladas por certo tipo de escrita e de experiência, autorizando-nos assim a pensar em "estilos de antropologia" ou modos de representação etnográfica ${ }^{19}$.

Os textos etnográficos expressam valores, idéias, sensibilidades, enfim, "estruturas de significados e pensamentos", às vezes muito mais relacionados aos antropólogos do que aos nativos em cena. Conclui-se que a etnografia náo se restringe a uma estratégia de trabalho de campo com fins à descrição das culturas nativas em termos de performances textuais. Esta também dramatiza muito das experiências dos antropólogos. A etnografia, então, performatiza um modo de ação

19. No Brasil, o antropólogo Roberto Cardoso de Oliveira (1995) tem se destacado na análise dos estilos de antropologia produzidos no centro e na periferia do sistema mundial. reflexiva na qual, por meio da escrita transformada em narrativa, personagens são acionados, verdades relativizadas, sentimentos ritualizados, enfim, culturas são inventadas. Em suma, podese dizer que a etnografia constitui uma importante categoria de pensamento na antropologia ${ }^{20}$.

\section{A magia de Mauss}

A obra de Marcel Mauss (1872-1950) aparece como um exemplo oportuno e fecundo para se pensar o alargamento da noção de etnografia na antropologia moderna. Neste artigo será possível oferecer apenas algumas notas introdutórias sobre, o que se poderia dizer, sua "performance etnográfica”.

Inicialmente, pode-se perguntar qual a razão de se tomar como exemplo para a reflexão desenvolvida nesse texto um antropólogo que nunca realizou "trabalho de campo" no sentido estrito do termo. É no mínimo curioso Mauss ter proposto um Manual de etnografia (1993), trabalho este interrompido pela eclosão da guerra nos anos 40, mas publicado em 1947 pelo esforço de um de seus alunos. Esta obra constitui a versão estenografada das suas "instruções de etnografia descritiva”, desenvolvida no Institute d'Ethnologie da Universidade de Paris, entre os anos de 1926-1939. Contudo, o fato de Mauss não ter "nunca praticado a observação etnográfica”, adverte Denise Paulme em prefácio ao Manual, não significa que não tenha produzido obra de etnografia. A exemplo do que dizem algumas leituras sobre Lévi-Strauss, às quais vêem na sua experiência nova-yorkina seu verdadeiro trabalho de campo, pode-se dizer que também a única e verdadeira etnografia de Mauss foi a sua própria

20. Concordo com Gonçalves (2004) em relação a noção de patrimônio, que também a etnografia, pensada como categoria de pensamento, designa um modo de ação reflexiva e de performance que deve ser vivido e sentido no cotidiano. 
sociedade e, em particular, sobre o "campo" da antropologia ${ }^{21}$.

Não por acaso os primeiros escritos de Mauss têm como preocupação principal a construção do "campo da sociologia", numa época em que a fronteira entre esta e a antropologia ainda não estava bem definida. Não se trata somente de uma herança do tio, Durkheim, mas sim um projeto de etnologia (no sentido de uma antropologia comparada e, metodologicamente, praticada por Mauss em sua obra), voltada para a superação da distância entre o primitivo e o civilizado, como sugere a leitura de Merleau-Ponty (1989). Advém desta proposta a ênfase nos estudos sobre representaçóes coletivas e sistemas de classificaçóes desenvolvidos desde os primeiros trabalhos, apontando para a complexidade e sofisticação do pensamento simbólico nas sociedades primitivas. Estes estudos revelam também outra preocupação fundamental de Mauss: a de identificar e analisar algumas das principais categorias do pensamento humano ${ }^{22}$.

21. Mauss faz exatamente aquilo que os etnógrafos fazem quando vão a campo, transformando o exótico em familiar. Inversamente, ele estranha e transforma o familiar em exótico, em algo que merece ser investigado e conhecido. A julgar pela observação de um de seus alunos, Dumont (1985), são os homens concretos (como o "francês médio" ou o "melanésio desta ou daquela ilha”) em sua própria sociedade, com suas açóes e representações em torno do corpo, da religião, da alimentação etc., que servem de parâmetro para Mauss desenvolver suas "instruçôes de etnografia descritiva".

22. Um sobrevôo na obra de Mauss nos revela sua preocupação com as representaçôes coletivas. Já em 1899, juntamente com Henri Hubert, publica o "Ensaio sobre a natureza e função do sacrifício”. Em 1901/1902 vêm à tona os estudos sobre o campo da sociologia e "O ofício do etnógrafo". Logo em seguida, Mauss dá início à série de estudos sobre representaçóes coletivas com o "Esboço de uma teoria geral da magia" (1902/1903). No mesmo ano, aparece "Algumas Formas Primitivas de Classificação", escrito em parceria com Durkheim e, no seguinte, é a vez do "Ensaio sobre as variações sazoneiras das sociedades esquimós". Dando um salto para os anos 20, aparecem
Embora ausente da lista de Geertz, o nome de Mauss pode ser incorporado ao dos "fundadores de discursividade" na antropologia moderna, isto é, aos "estudiosos que ao mesmo tempo tem estabelecido suas obras com certa determinação e construído teatros de linguagem a partir dos quais toda uma série de outros atuam, de maneira mais ou menos convincente, e, sem dúvida, seguirão atuando ainda por um longo período de tempo" (1997: 31). Numa linha de interpretação radical e provocativa, Alain Caillé vê no "Ensaio sobre a dádiva": "as linhas mestras não apenas de um paradigma sociológico entre outros, mas do único paradigma sociológico que se possa conceber e defender" (1998: 11). Mesmo que Caillé declare ser o espírito de Mauss tomado por um verdadeiro "horror à sistematização", no conjunto a obra de Mauss parece formar um "sistema" bastante coerente e integrado, embora goze de um caráter aparentemente anárquico ${ }^{23}$.

A compreensão da obra de Mauss não está separada de sua trajetória biográfica, o que, na interpretação de Fournier (1993), significa analisar como o sábio e o militante socialista participam do texto. A exemplo do próprio "Ensaio", de 1925, Mauss fez de sua vida uma

os estudos sobre "A expressão obrigatória dos sentimentos" (1921); a "Mentalidade primitiva" (1923); "As relaçôes reais e práticas entre a psicologia e a sociologia" (1924). E, em 25, surge o clássico "Ensaio sobre a Dádiva”. Nesta década surgem ainda outros trabalhos na linha das representaçóes coletivas sobre a morte (1926) e sobre o "gracejo" (1926), período que também inicia suas "Instruçóes de etnografia descritiva”, interrompidas pela Segunda Guerra. Antes, porém, surgem os últimos trabalhos que se tornariam referências na antropologia: "As técnicas corporais" (1934) e "Uma categoria do espírito humano - a noção de pessoa, a noção de 'Eu'” (1938).

23. Fournier (s/d) declara que a obra de Mauss é multiforme, difícil e cheia de ambigüidades. Além do já citado trabalho de Fournier, estou tomando como referência: Lévi-Strauss (1974); Oliveira (1979); Dumont (1985); Founier (1993; 2003). 
forma de dádiva sociológica e política, sugere o biógrafo canadense. Nessa perspectiva, as raízes do "Ensaio sobre a dádiva" já se encontram no "Ensaio sobre a natureza e a função do sacrifício", publicado em 1899 em colaboraçáo com Henri Hubert. Complementar a essa interpretação, gostaria de propor uma outra fonte de leitura, a partir do "Esboço de uma teoria geral da magia", publicado em 1903, também em colaboraçáo com Henri Hubert, no qual o destaque vai para a dimensão ritual do "fazer". Tal ênfase leva-nos a afirmar que a raiz do Manual de etnografia encontra-se na teoria da magia de 1903/0424.

Seguindo a sugestão de Giumbelli (1997) e estendendo-a ao conjunto da obra de Mauss, "Esboço a uma teoria geral da magia" aparece como um texto seminal a partir do qual a obra de Mauss vai sendo construída. É como se ele colocasse em prática a idéia que ajudava esclarecer, realizando assim, ao longo de sua obra, trabalho semelhante ao de um mago. Como os xamãs nas sociedades primitivas que fornecem um mito, uma linguagem a partir da qual os doentes, os iniciados, podem organizar suas ansiedades, suas dores, Mauss era visto por muitos de seus alunos como uma espécie de "guru" (sábio espiritual e intelectual), alguém que lhes fornecia (no sentido da dádiva) um "sistema de referência" por meio do qual podiam se orientar. Segundo Dumont, "graças a Mauss, tudo, mesmo o gesto mais insignificante, adquiria um sentido para nós" (1985: 181). Talvez isto ajude a explicar um pouco seu poder de sedução sobre os alunos. Mas a razão principal pela qual o "carisma” de Mauss se mostra eficaz não reside somente na personalidade extraordinária do "humanista" que "sabia tudo", diziam seus

24. Uma leitura de Mauss, de trás para frente, começando pelos últimos trabalhos até atingir os estudos iniciais sobre magia, revela não só uma continuidade, mas também outras dimensôes até então domesticadas pela visão tradicional e holista, no caso, o individualismo e a teoria da ação social. alunos, mas, sobretudo, em decorrência da posição que ocupou no campo da antropologia. Como apontou acerca dos agentes da magia (mágicos, feiticeiros, xamãs), cuja eficácia simbólica deriva dos sistemas de crenças e das posiçóes liminares que estes ocupam na sociedade, Mauss também parecia assumir uma posição até certo ponto liminar frente à dominante sociologia de Durkheim quanto ao amplo, aberto e ainda indefinido campo da antropologia ${ }^{25}$.

É dentro deste quadro que podemos entender a performance etnográfica de Mauss à luz da sua teoria da magia. A compreensão da magia como sistema ritual de crenças (representaçôes) e práticas (açôes) simbólicas, cuja eficácia consiste na produçáo de sentido, está na base da própria antropologia de Mauss. O que interessa a Mauss é, antes, o ato de fazer do que o feito, o ato de dizer do que o dito, o ato de rezar do que a reza, o ato de curar do que a cura. Para ele, vale lembrar, importa observar o que é dado e o que é dado é o que o romano, o ateniense, os franceses fazem quando fazem suas rezas, suas leis etc. Também o mágico é alguém que se faz, pois "não há mágico honorário e inativo. Para ser mágico, é necessário fazer magia...” (1974:

25. Do ponto de vista da "sociologia da biografia" todo intelectual típico de sua época concentra as características de seu grupo, diz Fournier: "Marcel Mauss abrange o que poderíamos denominar uma biografia coletiva, pois inclui tanto uma apresentação dos membros da equipe de L'année sociologique, como um estudo das instituiçóes de ensino superior Escola Prática de Estudos Superiores, Collège de France e ainda uma análise do desenvolvimento de disciplinas científicas (história das religiôes, antropologia, sociologia)" (2003: 3-4). Mas toda biografia traz implícito o risco da hagiografia: a canonização do Mauss pioneiro e/ou pai fundador. Ainda, segundo Fournier (1993), Mauss ocupou durante muito tempo uma posição marginal no sistema universitário francês, o que o colocou ao lado da pesquisa e não do ensino. Este fato, além de ter relevância sociológica para a compreensão da obra de Mauss, parece reforçar a dimensão performativa de sua etnologia. 
116), diz o próprio Mauss. Ele entende a magia como uma "idéia prática" na qual as ações e as representaçóes, a performance ritual e o sistema de crenças, não estão separados, mas, ao contrário, formam um único processo simbólico traduzido em termos de "arte de fazer". A magia é portadora de uma significativa qualidade performativa que parece inscrita nos rituais da prece, das trocas simbólicas, do "fazer" etnografia ${ }^{26}$.

Quando ultrapassa o campo estabelecido da sociologia das representaçóes coletivas, Mauss parece interessado em projetar uma teoria da ação social. Sem romper com as representaçóes sociais, Mauss pensa as "categorias do entendimento humano" como idéias de natureza prática, construídas historicamente. $\mathrm{O}$ estudo sobre "A noção de pessoa, a noção de 'Eu'", de 1938, é, sem dúvida, o melhor exemplo disto. Procurando superar o etnocentrismo dos sociólogos europeus, Mauss dá atenção especial às categorias (teorias) nativas. Para ele, as categorias fazem a mediaçáo entre o pensamento e a realidade, aproximando-se da proposta de uma antropologia da experiência ${ }^{27}$. Daí a importância que o Manual de etnografia adquire na obra de Mauss. Mesmo que na visáo de Dumont as instruções apresentem um caráter tão geral que assumem um ar de lugar-comum, tais instruçóes - por se voltarem para o mundo concreto do fazer cotidiano, das técnicas corporais, das trocas cerimoniais etc., enfim, da investigação exaustiva e microscópica no estilo de uma "descrição densa" - são de capital importância para se entender a proposta de Mauss.

26. Reforçando a antropologia da performance no campo da "fala", os inúmeros estudos de Malinowski, LéviStrauss e Evans-Pritchard enfatizam o poder das palavras (oralidade) nos rituais mágicos. Mesmo a escrita tem a sua magia. Vale ressaltar que Mauss dá grande atenção às palavras, salienta Fournier (1993).

27. Basta lembrar a importância da categoria "mana" nos sistemas de trocas simbólicas. Sobre a proposta da antropologia da experiência, ver Turner e Bruner (1986).
Se em antropologia social, diz Geertz, "o que os praticantes fazem é etnografia” (1978: 15), então Mauss não foge à regra. Como nas performances verbais dos rituais mágicos, a escrita de Mauss não só fala da magia, mas póe em prática um sistema mágico ao "fazer" sociologia ou antropologia. As análises de Dumont (1985) e Oliveira (1979) convergem para este ponto: o primeiro destaca o fato de a Sociologia e a Antropologia na França terem atingido seu "estágio experimental" com Mauss; o segundo, afirma que "o fazer Sociologia - melhor diríamos, Antropologia - parece-me ser o seu melhor ensinamento" (1979: 23). Mas, engana-se quem vê no Manual de etnografia uma "receita para se fazer antropologia". Resultado de um processo que se desenvolve a partir de suas preocupações com o campo sociológico, o Manual funciona como uma espécie de "cartografia do pensamento" ou "mapa cognitivo" sobre o "estado da arte" da antropologia à época de Mauss. Na verdade, o Manual não é um manual de etnografia, trata-se antes de uma (meta)etnografia do campo da antropologia, ainda em desenvolvimento. Mauss é, talvez, o melhor exemplo de que a etnografia começa e termina em casa e de que o "campo", como pensa Clifford, parafraseando Certeau, "nunca é dado ontologicamente. É discursivamente mapeado e praticado corporalmente" (1997: 54). Dumont sabia disso, e viu no mestre o significado profundo da etnografia, alguém que, misturando carisma e sabedoria, magia e dádiva, "recebera do céu a graça especial de ser um homem de campo sem sair de sua poltrona" (1985: 183). Em suma, Mauss, como Benedict em O Crisântemo e a Espada, desloca a noção convencional de que "o campo é um lar longe do lar", e, por meio de seu Manual, amplia o sentido do "campo etnográfico" na medida em que explicita a natureza performática da etnografia. 


\section{Uma categoria heurística}

A etnografia, tal como entendida no pensamento antropológico moderno, tem uma história: o seu significado não foi sempre o mesmo. Longe de pretender ter abordado todos os problemas colocados pela etnografia ao campo da antropologia e de sua inscriçáo no conjunto da obra de Mauss, e acreditando como Geertz no final de "Uma descrição densa - por uma teoria interpretativa da cultura" que "não há conclusões a serem apresentadas; há apenas uma discussão a ser sustentada” (1978: 39), duas ou três idéias podem ser destacadas neste final.

Conferir à etnografia a qualidade de categoria de pensamento na Antropologia Social e Cultural Moderna significa pensá-la como uma categoria heurística na medida em que permite analisar algumas das principais performances narrativas da disciplina antropológica. Em outras palavras, a etnografia é, ela mesma, uma chave metodológica para se penetrar no coração do pensamento e da prática antropológica. Se aceito esse pressuposto um mundo de possibilidades, problemas e descobertas, obtidas por meio do trabalho reflexivo, abre-se à nossa frente denunciando sua qualidade performativa, inovadora e cognitiva. Como nos lembra Mariza Peirano, a teoria e a história da antropologia se confundem com o "fazer" etnográfico, afinal, “a pesquisa etnográfica é o meio pelo qual a teoria antropológica se desenvolve e se sofistica quando desafia os conceitos estabelecidos pelo senso comum no confronto entre a teoria que o pesquisador leva para o campo e a observação da realidade 'nativa' com a qual se defronta” (1995: 135-136). É quando também passamos a compreender melhor a própria história da disciplina ${ }^{28}$.

28. Peirano lembra ainda a importância que a comparação adquire em todo este processo, relativizando o próprio relativismo ingênuo e/ou ideológico que parece contaminar os detratores da etnografia.
Com efeito, a etnografia náo representa a solução de todos os problemas da antropologia, mas também náo consiste na causa de todos os seus males. É preciso estar atento para se evitar cair nas armadilhas do que Eunice Durham, avaliando a produção antropológica no espaço urbano no Brasil, chamou de "deslize semântico", isto é, quando alguns conceitos como "classe", "ideologia”, "pessoa", "ethos", "identidade" etc, sofrem um processo de despolitização, perdendo sua vinculação teórica e poder de crítica cultural. A etnografia não está imune a este risco. No entanto, creio que parte dos motivos que sugerem o perigo de "deslize semântico" (eminentemente relativista), deve-se à sua própria qualidade performativa ${ }^{29}$. Afinal, a etnografia, como um gênero de performance narrativa, realiza a mediação entre o campo e a escrita, a teoria e a prática, o pensamento antropológico e a experiência individual do etnógrafo. De certa forma, ela fornece os fios narrativos que permitem fazer a uniáo dos extremos no campo antropológico, embora esta se dê de forma reflexiva, incompleta e dramaticamente densa.

\section{The ethnography as category of thought in modern anthropology}

abstract The innumerous possibilities and issues, put forward by ethnography to epistemological reflection in anthropology, makes it an important category of thought, capable of revealing the meaning of anthropologists works, i.e., their making. Therefore, ethnography can be seen as a genre of performance whose meaning surpasses the frontiers of native culture reaching the cultural field

29. Também Almeida (2004) chama atenção para a "objetificaçâo" da etnografia em tempos atuais na medida em que este processo de reificação denuncia antes os usos subjetivistas ao qual está exposta do que a sua objetividade metodológica. 
of the anthropologist. Performance, in this study, represents a mode of social auto-reflexivity in which the anthropologist, by making use of narrative, searches to enlarge the "field" of anthropology. The goal of this text is to point out a few moments in this process of ethnographic reflexivity, pointing out the writings of Marcel Mauss (1872-1950) as a privileged example.

keywords Ethnography. Performance. Narrative. Marcel Mauss

\section{Referências bibliográficas}

ALMEIDA, Mauro W. B. 2004. "A Etnografia em Tempos de Guerra - Contextos Temporais e Nacionais do Objeto da Antropologia”. In. F. Peixoto et al (orgs.), Antropologia, Histórias, Experiências. Belo Horizonte: Editora UFMG, p. 61-77.

AUSTIN, John L. 1990. Quando Dizer é Fazer - Palavras e Ação, tradução de Danilo Marcondes de Souza Filho, Porto Alegre: Artes Médicas.

BATESON, Gregory. [1958]. Naven - Estudio de los Problemas Sugeridos por Una Visión Compuesta de la Cultura de Una Tribu de Nueva Guinea Obtenida desde Tres Puntos de Vista, traducción de Ramón M. Castellote, Madrid: Ediciones Jucar, 1990.

BENJAMIN, Walter. [1936]. "O Narrador - Consideraçóes sobre a Obra de Nikolai Leskov”. In J. M. Gagnebin (Prefácio), Magia e Técnica, Arte e Politica: Ensaios sobre Literatura e História da Cultura, tradução de Sérgio Paulo Rouanet, $7^{a}$ ed. São Paulo: Brasiliense, 1994 (Obras Escolhidas, v. 1), p. 197-221.

BOON, James. 1993. Otras Tribus, Otros Escribas: Antropologia Simbólica en el Estudo Comparativo de Culturas, Historias, Religiones y Textos, traducción de Stella Mastrangelo, México: Fondo de Cultura Económica.

BOURDIEU, Pierre. [1976]. "O Campo Científico" In R. Ortiz (org.), Sociologia, tradução de Paula Montero \& Alicia Auzmendi. São Paulo: Ática, coleção Grandes Cientistas Sociais (39), 1983, p. 122-155,

BRUNER, Edward. 1986. "Ethnography as Narrative". In E. Bruner; V. Turner (eds.), The Anthropology of Experience. University of Illinois Press, p. 139-155.

CAILLÉ, Alan. 1998. "Nem Holismo Nem Individualismo Metodológicos - Marcel Mauss e o Paradigma da Dádiva”. Revista Brasileira de Ciências Sociais, 13 (38): 5-38.

CASAL, Adolfo Yáñez. 1996. Para uma epistemologia do discurso e da prática antropológica, Lisboa: Cosmos.
CLIFFORD, James. 1997. "Spatial Practices: Fieldwork, Travel, and the Disciplining of Anthropology”. In Routes - Travel and Translation in the Late Twentieth Century. Cambrigde: Harvard University Press, p. 5291.

1998. A Experiência Etnográfica: Antropologia e Literatura no Século XX. J. R. Gonçalves (org.), tradução de Patricia Farias, Rio de Janeiro: UFRJ.

COPANS, Jean. 1981. Críticas e Politicas da Antropologia, tradução de Manuela Torres, Lisboa: Edições 70.

DaMATTA, Roberto. 1978. "O Ofício de Etnólogo ou como ter "Anthropological Blues". In E. Nunes (org.), A Aventura Sociológica - Objetividade, Paixão e Improviso e Método na Pesquisa Social. Rio de Janeiro: Zahar, p. 23-35.

DOUGLAS, Mary. [1987]. Como as Instituiçóes Pensam, tradução de Carlos Eugênio Marcondes de Moura. São Paulo: EDUSP, 1998.

DUMONT, Louis. [1985]. O Individualismo - Uma Perspectiva Antropológica da Ideologia Moderna, tradução de Álvaro Cabral. Rio de Janeiro: Rocco, 1993.

FEYERABEND, Paul. [1977]. Contra o Método, tradução de Octanny Mota \& Leônidas Hagenberg, $3^{\text {a }}$ ed. Rio de Janeiro: Francisco Alves, 1989.

FOURNIER, Marcel. 1993. "Marcel Mauss ou A Dádiva de Si”. Revista Brasileira de Ciências Sociais, 21 (8): 104-112.

2003. "Para Reescrever a Biografia de Marcel Mauss.”. Revista Brasileira de Ciências Sociais, 18(52): 5-13.

1994. Marcel Mauss. Paris: Fayard.

GEERTZ, Clifford. 1978. A Interpretação das Culturas, s/t. Rio de Janeiro: Zahar.

[1988]. El Antropólogo como Autor, traducción de Alberto Cardín, Barcelona: Paidos, 1997.

[1968]. Observando o Islá - O Desenvolvimento Religioso no Marrocos e na Indonésia, tradução de Plínio Dentzien. Rio de Janeiro: Jorge Zahar Editor, 2004.

GIUMBELLI, Emerson. 1994. “Antropólogos e Seus Sortilégios - Uma Releitura de 'Esboço de Uma Teoria da Magia' de Mauss e Hubert”. Cadernos de Campo. 4: 21-39.

GONÇALVES, José Reginaldo. 2003. "O Patrimônio como Categoria de Pensamento”. In R. Abreu; M. Chagas (orgs.), Memória e Patrimônio - Ensaios Contemporâneos, Rio de Janeiro: DP\&A, p. 21-29.

GRIMSHAW, Anna. 2001. The Ethnographer's Eye - Ways of Seeing in Modern Anthropology, Cambridge University Press. 
HANDLER, Richard. 1990. "Ruth Benedict and The Modernist Sensibility”. In M. Manganaro (ed.), Modernist Anthropology: From Fieldwork to Text. New Jersey: Princeton University Press, p. 163-182.

KILANI, Mondher. 1994. L'Invention de L'Autre - Essais sur le Discours Anthropologique. Editiones Payot Lausanne.

KUPER, Adam. 1978. Antropólogos e Antropologia, tradução de Álvaro Cabral, Rio de Janeiro: Francisco Alves.

LANGDON, Ester Jean. 1999. "A Fixação da Narrativa: Do Mito para a Poética de Literatura Oral". Horizontes Antropológicos - Cultura Oral e Narrativas, 5(12): 13-36.

LÉVI-STRAUSS, Claude. [1950]. "Introdução: A Obra de Marcel Mauss". In M. Mauss. Sociologia e Antropologia 1 e 2, traduçáo de Lamberto Puccinelli, São Paulo: EPU-EDUSP, 1974.

MARCUS, George; CUSHMAN, Dick. 2003. "Las Etnografias como Textos". In C. Reynoso (ed.), El Surgimiento de La Antropología Posmoderna, traducción de Carlos Reynoso, Barcelona: Gedisa, p. 171-213.

MAUSS, Marcel.[1950]. Sociologia e Antropologia 1 e 2, tradução de Lamberto Puccinelli, São Paulo: EPUEDUSP, 1974.

1979. Antropologia. In R. C. Oliveira. (org.), traduçáo de Regina Moraes Morel, Denise Maldi Meirelles \& Ivonne Toscano. São Paulo: Ática, coleção Grandes Cientistas Sociais (11).

. [1968]. Ensaios de Sociologia, tradução de Luiz João Gaio \& J. Guinsburg, São Paulo: Perspectiva, 1981.

[1967]. Manual de Etnografia, tradução de J. Freitas e Silva. Lisboa: Dom Quixote, 1993.

MERLEAU-PONTY, Maurice. 1960. "De Mauss à Claude Lévi-Strauss" In Textos Selecionados, tradução de Marilena Chauí. São Paulo: Nova Cultural, coleção Os Pensadores, vol. XLI, 1989, p. 141-154,.
OLIVEIRA, Roberto Cardoso de. 1979. "Introdução a Uma Leitura de Mauss". In M. Mauss, Antropologia, tradução de Regina Moraes Morel, Denise Maldi Meirelles \& Ivonne Toscano São Paulo: Ática, coleção Grandes Cientistas Sociais (11), p. 7-50. 1988. Sobre o Pensamento Antropológico, Rio de Janeiro-Brasília: Tempo Brasileiro-CNPq. 1995. Estilos de Antropologia, Campinas: UNICAMP.

[1999]. O Trabalho do Antropólogo, 2a ed. São Paulo-Brasília: UNESP-Paralelo, 2000.

PEIRANO, Mariza. 1995. A Favor da Etnografia. Rio de Janeiro: Relume-Dumará.

PULMAN, Bertrand. 1988. "Por une Histoire de la Notion de Terrain". Gradhiva: Revue d'Histoire e d'Archives de l'Anthropologie, 5: 22-30.

SAHLINS, Marshal. [1987]. Ilhas de História, tradução de Bárbara Sette. Rio de Janeiro: Jorge Zahar, 1990.

SANTOS, Boaventura de Souza. 1989. Introdução à Uma Ciência Pós-moderna, Rio de Janeiro: Graal.

SILVA, Rubens Alves da. 2005. "Entre 'Artes' e 'Ciências': A Noção de Performance e Drama no Campo das Ciências Sociais". Horizontes Antropológicos - Antropologia e Performance, 2(24): 35-65.

STOCKING Jr., George W. 1983. "The Ethnographic Sensibility of the 1920s and The Dualism of the Anthropological Tradition”. In G. Stocking Jr (ed.), Romantic Motives-Essays on Anthropological Sensibility. Wisconsin: The University of Wisconsin Press, vol. 6, p. 209-276.

TRAJANO FILHO, Wilson. 1988. "Que Barulho é esse, o dos Pós-Modernos?”. Anuário Antropológico, 86: 133-151.

TURNER, Victor W. 1988. The Anthropology of Performance. New York, PAJ Publications.

WAGNER, Roy. 1981. The Invention of Culture. Chicago: The University of Chicago Press.

\section{autor Gilmar Rocha}

Professor do Departamento de Ciências Sociais / PUC - Minas

Doutor em Ciências Humanas (Antropologia Cultural) / UFRJ

Recebido em 06/03/2006

Aceito para publicação em 14/07/06 